\title{
Influence of Milling Techniques on the Performance of Wheat Straw Ash in Cement Composites
}

\author{
Abdul Qudoos ${ }^{1}$, Ehsanullah Kakar ${ }^{2}$, Atta ur Rehman ${ }^{1}$, In Kyu Jeon ${ }^{3}$ and Hong Gi Kim ${ }^{3, *}$ \\ 1 Department of Civil Engineering, Balochistan University of Engineering and Technology (BUET), \\ Khuzdar 89100, Pakistan; qudoos.engnr@gmail.com (A.Q.); attabrcian@gmail.com (A.u.R.) \\ 2 Balochistan University of Engineering and Technology (BUET), Khuzdar 89100, Pakistan; vc@buetk.edu.pk \\ 3 Department of Civil and Environmental Engineering, Hanyang University, Seoul 04763, Korea; \\ supermacy94@daum.net \\ * Correspondence: dmkg1404@hanyang.ac.kr; Tel.: +82-2-2220-4323
}

Received: 20 April 2020; Accepted: 6 May 2020; Published: 19 May 2020

\begin{abstract}
The worldwide production of cement is growing every year due to its increased use in the construction. Cement production is affiliated with an environmental concern as it contributes to the $\mathrm{CO}_{2}$ emissions. It is imperative to reduce the cement production by incorporating supplementary cementitious materials in the cement composites. In this research study, wheat straw ash (WSA) was used as an alternate of ordinary Portland cement. The ash was ground separately with a ball mill and a disintegrator mill as well as with a combination of both to enhance its pozzolanic efficiency. Mortar and paste specimens were made by substituting cement with WSA ( $20 \%$ by weight). Ash specimens were examined in terms of particle size distribution, $\mathrm{X}$-ray diffraction, and X-ray fluorescence analyses. The performance of the ash specimens in cement composites was examined via compressive and flexural strengths, and ultrasonic pulse velocity (UPV) tests. Isothermal calorimetric, thermogravimetric analyses (TGA), mercury intrusion porosimetry (MIP), and scanning electron microscopy (SEM) were also employed on the specimens. The results revealed that the particle size of the wheat straw ash specimens significantly reduced and specific surface area enhanced when ground with a combination of both milling techniques. Cement composites made with this type of ash demonstrated improved mechanical and physical properties, accelerated hydration reaction at the early ages, reduce calcium hydroxide content at the later ages, and densified microstructure.
\end{abstract}

Keywords: $\mathrm{CO}_{2}$ emissions; wheat straw ash; milling; isothermal calorimetry; Thermogravimetric analysis

\section{Introduction}

Cement is an important component of concrete and it is used widely in the construction industry and expected to be double by 2050 [1]. Worldwide production of cement is an environmental concern due to $\mathrm{CO}_{2}$ emission during the cement production. It has been estimated that about $8 \mathrm{~kg}$ of carbon dioxide is emitted in the atmosphere while producing $10 \mathrm{~kg}$ of cement [1-3]. This way, the production of cement account for $6-7 \%$ of worldwide $\mathrm{CO}_{2}$ emissions [3]. Apart from this, cement producing plants utilize a huge amount of energy which contributes to $3 \%$ of the universal consumption [4]. The $\mathrm{CO}_{2}$ emissions from cement industry are produced by combustion (30-35\%), decomposition of limestone (50-60\%), and the transportation of the materials (about 10\%) [5]. These emissions can be minimized by incorporating waste or raw materials as partial or full substitute of cement. These materials are most commonly known as supplementary cementitious materials (SCMs) [1]. For this purpose, utilization of SCMs such as fly ash, slag, silica fume, rice husk ash (RHA), wheat straw ash (WSA), etc. in the construction industry is gaining much attention. These materials contain an abundant amount of silica 
which causes excellent pozzolanic activity [6]. The utilization of these materials as substitute of cement can be a feasible solution for the decrease of carbon dioxide emissions [7].

The ashes obtained by burning agricultural residues has been widely used to replace cement. Most commonly used agricultural residue ashes (ARAs) are RHA, rice straw ash (RSA), sugarcane bagasse ash (BA), palm oil fuel ash (POFA), and corncob ash (CCA). Mehta [8] and Nair [9] reported that high specific surface area, porous microstructure, and high amount of amorphous silica make RHA make it an effective supplementary cementitious material. It has been reported in various studies that concrete containing RHA depicted improved mechanical performance, minor permeability, and amplified resistance to acid attack, corrosion, and carbonation $[10,11]$. In another study, it has been reported that mortar specimens made with $10 \%$ substitution of cement with RSA have demonstrated enhanced strength and impermeability compared to control mix [12]. Amin [13] investigated the usage of $\mathrm{BA}$ as a possible cement replacement material. He made concrete specimens by replacing cement with $20 \%$ of BA and investigated various properties. The results of his study reveal that concrete specimens containing BA displayed reduced chloride penetration and substantial early strength development. Jaturapitakkul et al. [14] stated that improved compressive strength and sulfate resistance was observed for concrete test specimens made with well-ground POFA. The results of the study conducted by Adesanya and Raheem [15] recommend replacement of cement with $8 \%$ CCA for structural concrete.

Among all agricultural residue ashes, WSA has not been thoroughly studied. Wheat is the major produced cereal crop in the world. In 2017-2018, European Union produced approximately 151.6 million metric tons of wheat and Pakistan produced 26.6 million metric tons of wheat production [16]. During production of every $10 \mathrm{~kg}$ of wheat, 13-14 $\mathrm{kg}$ of wheat straw is generated [17]. The unused wheat straw is burnt in open atmosphere which is a severe environmental concern. However, WSA is a rich source of silica making it an efficient pozzolanic material. Biricik et al. reported that burning wheat straw produced $8.6 \%$ of ash (73\% silica content) [18]. The efficacy of WSA as a pozzolanic and filler material in cement mixtures is reported in previous research studies [18-20]. They have concluded that addition of WSA improved the mechanical properties of cementitious composites [18,19]. Apart from this, WSA has been reported to possess filling property. For instance, in a study, it has been reported that the hardened properties of cement mortars are enhanced due the filling ability of WSA [20]. Moreover, the addition of WSA enhances the durability-related properties of cementitious materials. For example, replacing a portion of sand or cement with WSA results in reduced absorption and improved resistance to acid and sulfate attack [21,22]. Similarly, in another study, it has been concluded that freeze-thaw resistance of concrete specimens containing WSA enhanced [23].

Based on the findings indicated in the existing literature, it is evident that WSA possess the filler aswell as pozzolanic properties. However, due to its lower pozzolanic activity, it has not been thoroughly studied. The pozzolanic activity of the ashes can be increased by applying grinding procedures. Grinding decreases the particle size and enhances the surface area. This adds nucleation sites which facilitates the precipitation of additional hydrates [24]. The focus of the present study is to select a suitable grinding procedure for obtaining a high pozzolanic and filler material. In this study, WSA specimens were ground separately with a ball mill and a disintegrator mill as well as with a combination of both techniques. The ash attained after each grinding procedure was examined for particle size distribution (PSD), X-ray diffraction analysis (XRD), specific surface area, and X-ray fluorescence (XRF) analysis. Each kind of WSA was added as a cement replacement (20\% by weight) and paste and mortar specimens were made. Compressive, flexural, and UPV tests were conducted to assess the performance of each kind of WSA in cement composites. Additionally, isothermal calorimetric and thermogravimetric analyses (TGA), mercury intrusion porosimetry (MIP), and scanning electron microscopy (SEM) were employed. 


\section{Materials and Test Methods}

\subsection{Materials}

Cement (OPC) conforming to ASTM C150 [25] with a specific surface area of $3200 \mathrm{~cm}^{2} / \mathrm{g}$ was used for this research study. WSA was obtained by burning the straw at $670{ }^{\circ} \mathrm{C}$ for $5 \mathrm{~h}$ in a laboratory oven [26]. Burning of wheat straw at specified temperature and duration produced $8 \%$ of ash. The ashes were ground using a ball mill (60 min), a disintegrator mill (BioloMix 2000G, $32000 \mathrm{rpm}$ )(3 cycles each of $5 \mathrm{~min}$ ), and a combined milling technique (ball mill $45 \mathrm{~min}+$ disintegrator mill 3 cycles), referred as W1, W2, and W3, respectively. The ball mill comprised of a cylinder with dimensions of $\phi 500 \times 600 \mathrm{~mm}$. Cylinder was rotated at a rate of $350 \mathrm{rpm}$ which contained steel balls. Table 1 reports the chemical composition of WSA, OPC specimens used in the present study, and other ARAs reported in the literature.

Table 1. Chemical composition of used WSA and other ARAs.

\begin{tabular}{cccccccc}
\hline \multirow{2}{*}{ Composition } & \multicolumn{7}{c}{ Weight (\%) } \\
\cline { 2 - 7 } & OPC & $\begin{array}{c}\text { WSA (Present } \\
\text { Study) }\end{array}$ & RHA [11] & RSA [12] & POFA [14] & BA [13] & CCA [15] \\
\hline $\mathrm{SiO}_{2}$ & 20.81 & 65.71 & 91.9 & 76 & 57.7 & 87.4 & 66.38 \\
$\mathrm{AL}_{2} \mathrm{O}_{3}$ & 6.30 & 3.74 & 0.25 & 0.69 & 4.5 & 3.6 & 7.48 \\
$\mathrm{Fe}_{2} \mathrm{O}_{3}$ & 3.21 & 2.59 & 0.41 & 0.63 & 3.3 & 4.9 & 4.44 \\
$\mathrm{CaO}$ & 62.0 & 7.85 & 0.38 & 4.96 & 6.5 & 2.56 & 11.57 \\
$\mathrm{MgO}$ & 3.31 & 2.69 & 0.21 & 2.65 & 4.2 & 0.69 & 2.06 \\
$\mathrm{Na} 2 \mathrm{O}$ & - & 2.46 & 0.05 & 1.36 & 0.5 & 0.15 & 0.41 \\
$\mathrm{~K}_{2} \mathrm{O}$ & - & 3.28 & 2.78 & 9.89 & 8.2 & 0.47 & 4.92 \\
$\mathrm{P}_{2} \mathrm{O}_{5}$ & - & 1.68 & 0.36 & - & - & - & - \\
$\mathrm{SO}_{3}$ & 2.21 & 2.35 & - & 1.9 & 0.2 & 0.11 & 1.07 \\
$\mathrm{LOI}$ & 1.31 & 7.33 & 2.93 & - & 10.5 & 8.25 & - \\
\hline
\end{tabular}

\subsection{Mix Proportions and Experiments}

Mortar mixes were prepared using constant sand-binder and water-cement ratios of 2.75 and 0.4, respectively in accordance with ASTM C109 [27]. Table 2 reports the mix proportions. W1, W2, and W3 types ash were used to replace cement at a level of $20 \%$ (by weight) and denoted as W1/20, W2/20, and W3/20, respectively. Mortar cubes and prisms were made following ASTM C109 and ASTM C348 [27,28], respectively. After $24 \mathrm{~h}$, mortar specimens were detached from the molds and positioned in lime-rich water for further curing till designed testing age. Paste specimens were cast in poly vinyl chloride molds using a water-cement ratio of 0.4 . The molds were sealed and kept in a curing chamber for $24 \mathrm{~h}$ at $20^{\circ} \mathrm{C}$; and $90 \%$ relative humidity. After a period of $24 \mathrm{~h}$, the specimens were removed and kept in lime-saturated water for additional curing. The portions of the specimens crushed during compression testing were utilized to make specimens for SEM investigations. Thin specimens for SEM analysis were acquired and submerged in alcohol for 1 day then dried in a laboratory-scale oven at $60{ }^{\circ} \mathrm{C}$; in accordance with the protocol discussed in reference [29].

Table 2. Mix proportions of mortar mixes.

\begin{tabular}{ccccccc}
\hline \multirow{2}{*}{ Mix ID } & \multirow{2}{*}{ Cement (g) } & \multicolumn{3}{c}{ WSA (g) } & \multirow{2}{*}{ Sand (g) } & \multirow{2}{*}{ Water (g) } \\
\cline { 3 - 5 } & & W1 & W2 & W3 & & \\
\hline REF & 100 & 0 & 0 & 0 & 275 & 40 \\
W1/20 & 80 & 20 & 0 & 0 & 275 & 40 \\
W2/20 & 80 & 0 & 20 & 0 & 275 & 40 \\
W3/20 & 80 & 0 & 0 & 20 & 275 & 40 \\
\hline
\end{tabular}


The particle size distribution and specific surface area of the ashes after each grinding process was studied using particle size analyzer (Malvern Mastersizer 2000), and surface area analyzer (3 Flex, micromeritics instruments), respectively. X-ray fluorescence (XRF) (S8 Tiger) was used to obtain the chemical composition of the ash specimens. An X-ray diffractometer (RINT D/max 2500, $40 \mathrm{kV}, 30 \mathrm{~mA}$, scanning speed $2^{\circ} / \mathrm{min}$, wavelength $1.54 \AA$ ) was used to identify the amorphous and crystalline phases of $\mathrm{SiO}_{2}$ in the ash specimens. Compressive strength of the mortar specimens was examined using a universal testing machine (UTM) (Shimadzu, CCM-200A; Shimadzu Corporation, Japan) at curing ages of 7, 28, and 90 days. Three replicates were used for each mix. Flexural strength of mortar prims was measured following ASTM 348 using a three-point bending machine (AG-I, Shimadzu, $250 \mathrm{kN}$, Shimadzu Corporation, Japan). Three samples were tested for each mix. The heat released from the paste specimens were measured using an Isothermal calorimeter (TAM AIR, TA Instruments, USA) at $23{ }^{\circ} \mathrm{C}$ for $40 \mathrm{~h}$. Paste specimens were mixed and firmly sealed inside a high-density polyethylene (HDPE) container instantly after mixing and then placed inside the calorimeter. It is because of this reason initial peak could not be accurately measured. For TGA analysis, acetone-treated and dried powder specimens were acquired from the paste specimens after 28 days of curing using a thermogravimetric analyzer (TA instruments, TGA7 PERKIN ELMER). An ultrasonic pulse velocity (UPV) test was conducted on mortar prisms in accordance with ASTM C597 [30]. MIP was used to examine the porosity of mortar specimens at 7, 28 and 90 days. Specimens for MIP obtained at each curing age were placed in ethanol to stop hydration and then dried in a laboratory-scale oven at $60^{\circ} \mathrm{C}$ for $24 \mathrm{~h}$. For SEM test, Philips XL30ESEM was used to examine the microstructure of the mortar specimens.

\section{Results and Discussions}

\subsection{Properties of Ash Specimens}

Figure 1 displays the particle size distribution of the ash specimens obtained using different grinding techniques. Among all ash specimens, those ground only with disintegrator presented coarser particles in comparison with those ground using ball mill and combination of both techniques. The percentage of the finer particle was increased when ground with a combination of ball mill and disintegrator. Specific surface area of $14528 \mathrm{~cm}^{2} / \mathrm{g}, 7251 \mathrm{~cm}^{2} / \mathrm{g}$, and $16124 \mathrm{~cm}^{2} / \mathrm{g}$ was measured for W1, W2, and W3 ash specimens, respectively (Table 1).

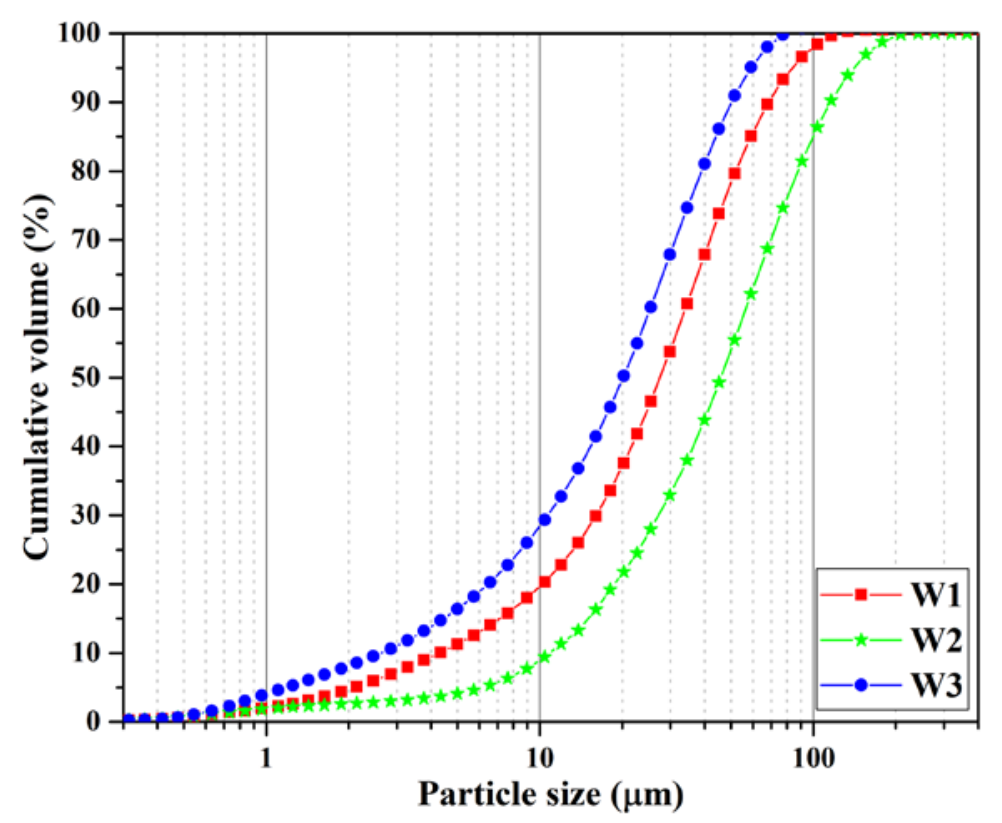

Figure 1. Distribution of particle size of WSA specimens. 
XRD results are shown in Figure 2. It can be seen that the peaks for crystalline silica $\left(\right.$ at $20^{\circ}$ ) reduced for W1 and W3 ash specimens as compared to that of W2 specimen. The decrease in height and broadening of the peak for silica is an indication of amplified amorphousness. It may be due to the availability of the inner amorphous silica due to extensive grinding [24]. The oxide composition of the ash specimens was determined via XRF analysis (Table 1). The combined percentage of $\mathrm{SiO}_{2}, \mathrm{Fe}_{2} \mathrm{O}_{3}$, and $\mathrm{Al}_{2} \mathrm{O}_{3}(72 \%)$ meet the least requirement of ASTM C618 [31] for a pozzolanic material. Table 2 shows the oxide composition of WSA used in the present study and other ARAs used in previous studies. It can be seen that RHA demonstrated highest content of silica while POFA presented the least content.

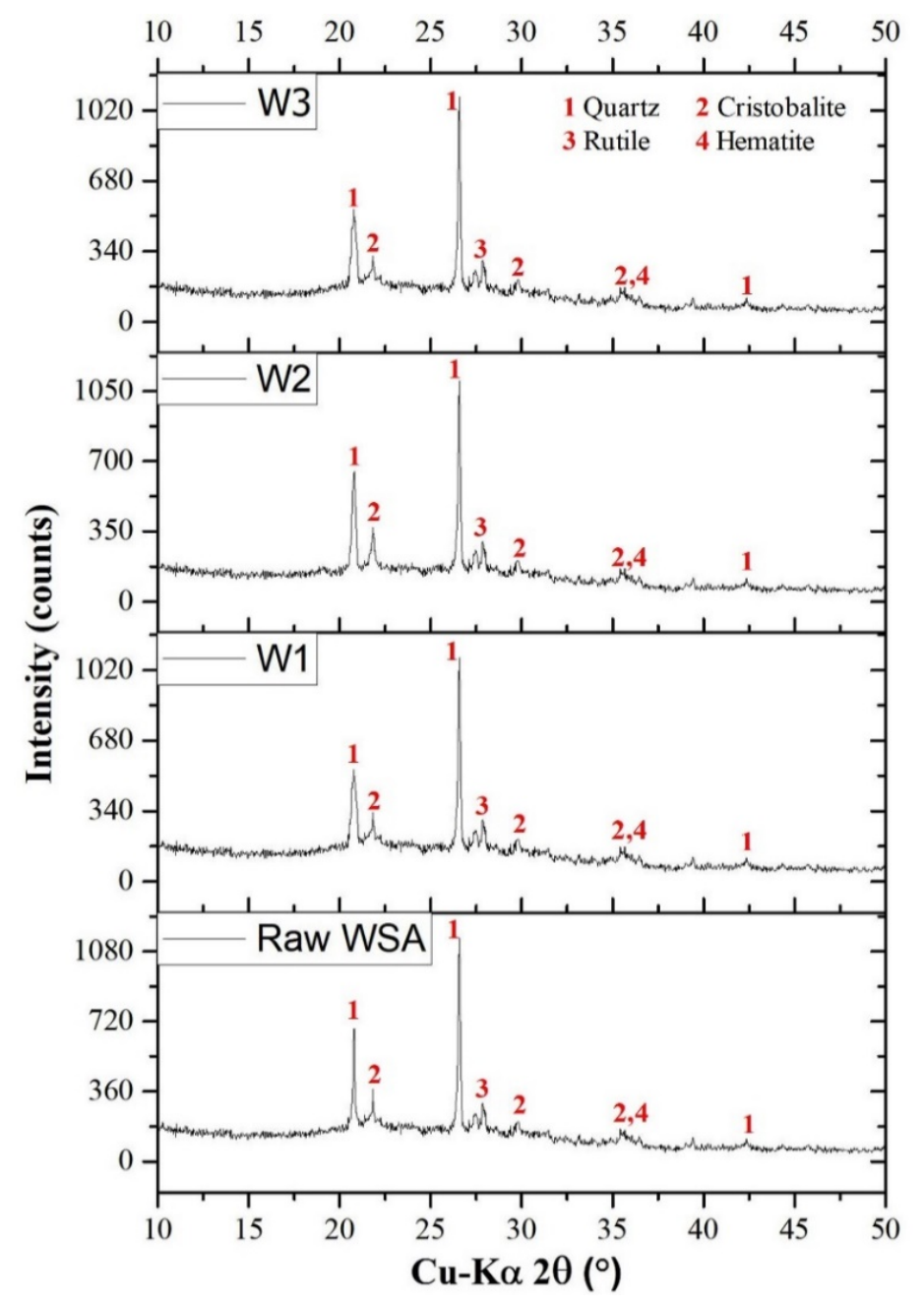

Figure 2. XRD pattern of WSA specimens.

\subsection{Mechanical Properties}

Figure 3 depicts the results of the compressive strength test for various mortar types. Compressive strength enhanced with increasing curing age. For instance, control (REF) mortar specimens demonstrated a compressive strength of $49.3 \mathrm{MPa}, 60.1 \mathrm{MPa}$, and $68.7 \mathrm{MPa}$ at 7, 28, and 90 days, respectively. Apart from this, the results clearly describe that the compressive strength increased for the specimens with finer ash particles (W1 and W3 types). For example, a compressive strength of $51.5 \mathrm{MPa}$, 63.4 $\mathrm{MPa}$, and 70.2 MPa was observed for $\mathrm{W} 2 / 20$ mortar specimens at 7, 28, and 90 days, respectively. W3/20 mortar specimens presented a compressive strength of $53.4 \mathrm{MPa}, 66.7 \mathrm{MPa}$, and $72.3 \mathrm{MPa}$ at 7, 28, and 90 days of curing, respectively. Apart from this, the addition of coarser ash particles 
reduced the compressive strength. The specimens containing 20\% W2 type ash particles demonstrated a compressive strength of $42.8 \mathrm{MPa}, 55.3 \mathrm{MPa}$, and $60.6 \mathrm{MPa}$ at 7, 28, and 90 days of curing, respectively.

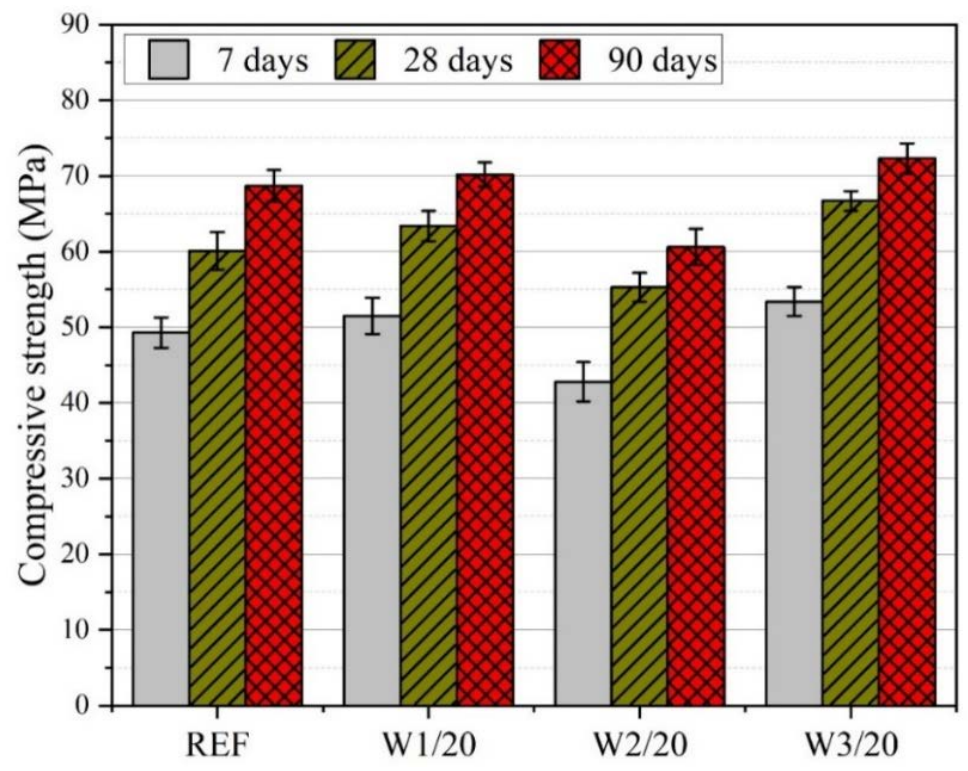

Figure 3. Compressive strength of mortar specimens.

Figure 4 displays the results of flexure strength test conducted on various mortar specimens. Flexure strength increased with increasing curing age. For instance, control (REF) specimens demonstrated flexure strength of $7.51 \mathrm{MPa}, 9.1 \mathrm{MPa}$, and 9.72 $\mathrm{MPa}$ at 7, 28, and 90 days, respectively. Similar to the results of the compression testing, flexure strength increased with the inclusion of finer ash particles. For instance, a flexure strength of $7.86 \mathrm{MPa}, 9.25 \mathrm{MPa}$, and $9.78 \mathrm{MPa}$ was observed for W1/20 mortar specimens at 7, 28, and 90 days. Similarly, W3/20 mortar specimens demonstrated flexure strength of $7.92 \mathrm{MPa}, 9.84 \mathrm{MPa}$, and $10.05 \mathrm{MPa}$ at 7, 28, and 90 days of curing. On the other hand, the addition of coarser ash particles caused a reduction in flexure strength in comparison with the control mortar specimens. For example, W2/20 mortar specimens demonstrated a flexure strength of $7.05 \mathrm{MPa}, 8.48 \mathrm{MPa}$, and $9.13 \mathrm{MPa}$ at 7, 28, and 90 days of curing, respectively.

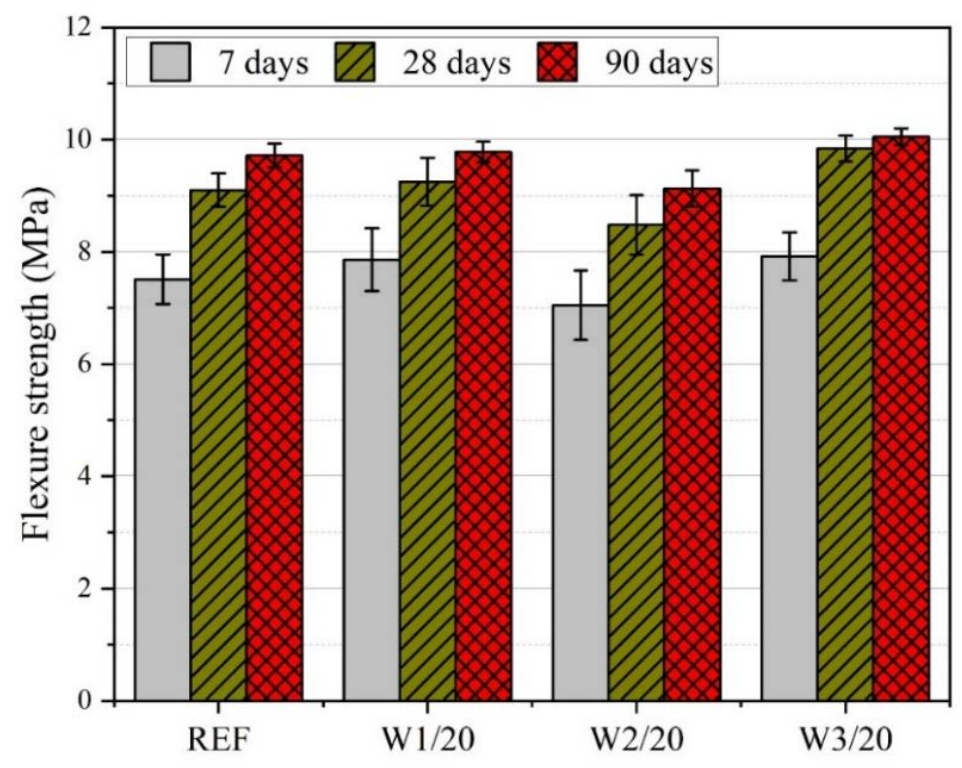

Figure 4. Flexure strength of mortar specimens. 
Highest strength was observed for the specimens made with ash particles ground with a combination of ball and disintegrator mills. Similar behavior was observed in a previous study [32]. The results of that study demonstrate that the incorporation of finely ground RHA amplified the pozzolanic reaction and refined the pore structure, which resulted in an improved strength. Cordeiro et al. [33] and Ganesan et al. [34] revealed that incorporating ultra-fine BA at an optimal content of $20 \%$ by weight of OPC resulted in improved strength values. Contrary to this, the specimens made with W2 ash particles caused a decrease in strength compared to the control specimens. It is due to the reason that the coarser ash particles negatively affect the nucleation effect and ultimately subside the strength [35].

\subsection{Isothermal Calorimetry}

Isothermal calorimetry was employed on various mixes to investigate the rate of reaction at the very early ages (up to $40 \mathrm{~h}$ ) as shown in Figure 5. Point A represents dissolution stage of cement in water, point $B$ indicates the dormant time, point $C$ represents hydration reaction at peak, point $D$ represents sulfate consumption, and point $\mathrm{E}$ indicates increased aluminate activity [36]. The results demonstrate that the peaks amplified and shifted to former times when ash had introduced. Figure 5 makes it obvious that the mixes with $\mathrm{W} 1$ and $\mathrm{W} 3$ ash particles showed prominently amplified heat release peaks compared to the mixes with $\mathrm{W} 2$ ash particles. For instance, at point $\mathrm{C}$ (hydration reaction at peak), a normalized heat flow of $3.62 \mathrm{~mW} / \mathrm{g}, 3.91 \mathrm{~mW} / \mathrm{g}, 3.62 \mathrm{~mW} / \mathrm{g}$, and $3.93 \mathrm{~mW} / \mathrm{g}$ was measured for REF, $\mathrm{W} 1 / 20, \mathrm{~W} 2 / 20$, and W3/30 specimens, respectively. It is mainly due to the amplified number of reaction sites for the finer ash particles which enhanced the hydration reaction $[24,37]$. The results of the study carried out by Cordeiro et al. [24] reveal that the ultrafine particles of SCBA caused an abbreviation of the induction period and amplified the peak heat release rate due to heterogeneous nucleation.

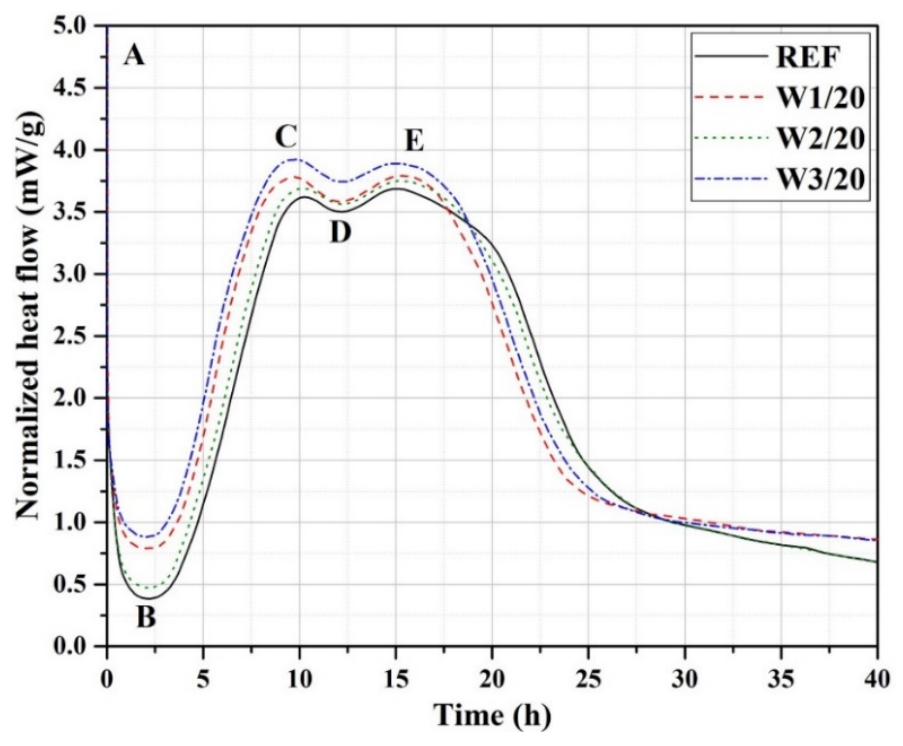

Figure 5. Heat release profiles of paste specimens.

\subsection{Thermogravimetric Analysis}

The degree of hydration at 28 days of hydration was measured via Thermogravimetric analysis. Figure 6 presents the results of TGA analysis for various specimens cured for 28 days. Three discrete phases were seen in the TG curves for all the specimens. Following Ref [38], major weight loss observed at $420-540^{\circ} \mathrm{C}$; corresponding to the decomposition of portlandite was used to measure the degree of hydration. Particularly, the weight loss in the range of $50-200^{\circ} \mathrm{C}$; can also be caused due to unbound 
water, hence the first phase may not be a correct indication of C-S-H amount [38]. The amount of CH was assessed according to the following formula [38]:

$$
C H(\%)=\left(\frac{M W_{C H}}{M W_{H 2 O}}\right) \times M W_{C H}(\%)
$$

where $M W_{C H}(\%), M W_{C H}$, and $M W_{H 2 O}$ represents the weight loss during the dehydration of $\mathrm{CH}$ as a percentage of the ignited weight (\%), the molecular weight of $\mathrm{CH}$, and the molecular weight of $\mathrm{H}_{2} \mathrm{O}$, respectively.

The tabulated data in Figure 6 shows the $\mathrm{CH}$ content calculated for various specimens. It is obvious that the control (REF) specimen demonstrated the highest content of $\mathrm{CH}(20 \%)$ amongst all the specimens. The specimens prepared with W3 ash particles depicted the least content $(13.9 \%)$ of calcium hydroxide followed by those with $\mathrm{W} 1$ ash particles $(14.9 \%)$. Contrary to this, a CH content of $18.2 \%$ was noticed for the specimens prepared with W2 ash particles. The results of TGA analysis suggest that the addition of WSA generated extra hydration products (C-S-H) by reacting with $\mathrm{CH}$. A prominent reduction in $\mathrm{CH}$ amount due to the incorporation of finer WSA particles indicates the nucleation effect. Also, the inner amorphous silica was made available for pozzolanic reactions due to the grinding of the particles of WSA [24]. Summarizing, the pozzolanic, filler and heterogeneous nucleation effects were responsible for the enhanced performance of the finer ash particles [24,37].

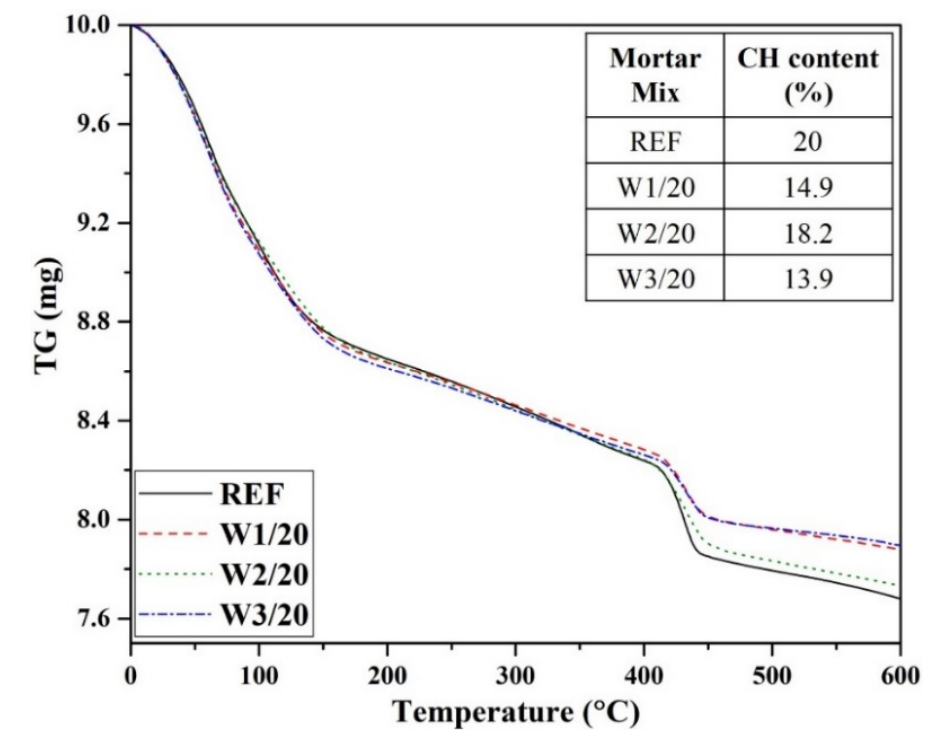

Figure 6. TG curves and calcium hydroxide content of paste specimens at 28 days.

\subsection{Mercury Intrusion Porosimetry}

Mercury intrusion porosimetry was carried out on the mortar specimens to examine the effect of WSA fineness on the overall porosity. Figure 7 illustrates the results of MIP analysis in terms of total porosity (\%) measured at 7 days, 28 days, and 90 days. It is obvious that porosity decreases with increasing curing age irrespective of the constituents of mixes. It is primarily credited to the formation of additional hydration products with age, thus resulted in a densified microstructure. At the age of 7 days, reference mortar specimen presented $15.82 \%$ total porosity whereas at the age of 28 days and 90 days this value reduced to $15.01 \%$ and $14.22 \%$, respectively. Furthermore, the inclusion of WSA triggered a decrease in the porosity of the mortar mixes irrespective of the replacement level. The decrease was more noticeable with the addition of finer WSA particles. For example, the total porosity for $\mathrm{W} 1 / 20$, W2/20, and $\mathrm{W} 3 / 20$ were measured $13.12 \%, 16.22 \%$, and $12.16 \%$ at 7 days; $12.27 \%$, $15.88 \%$, and $11.78 \%$ at 28 days; $11.54 \%, 15.05 \%$, and $10.68 \%$ at 90 days, respectively. It can be seen that total porosity reduced at the early ages as well. It means mainly filler effect attributed to the porosity 
reduction for the early ages and pozzolanic effect and filler effect imparted reduced porosity in the later ages [32,39]. Cordeiro et al. [33] reported that adding ultra-fine BA improved the pore structure and resulted in an enhanced durability-related performance.

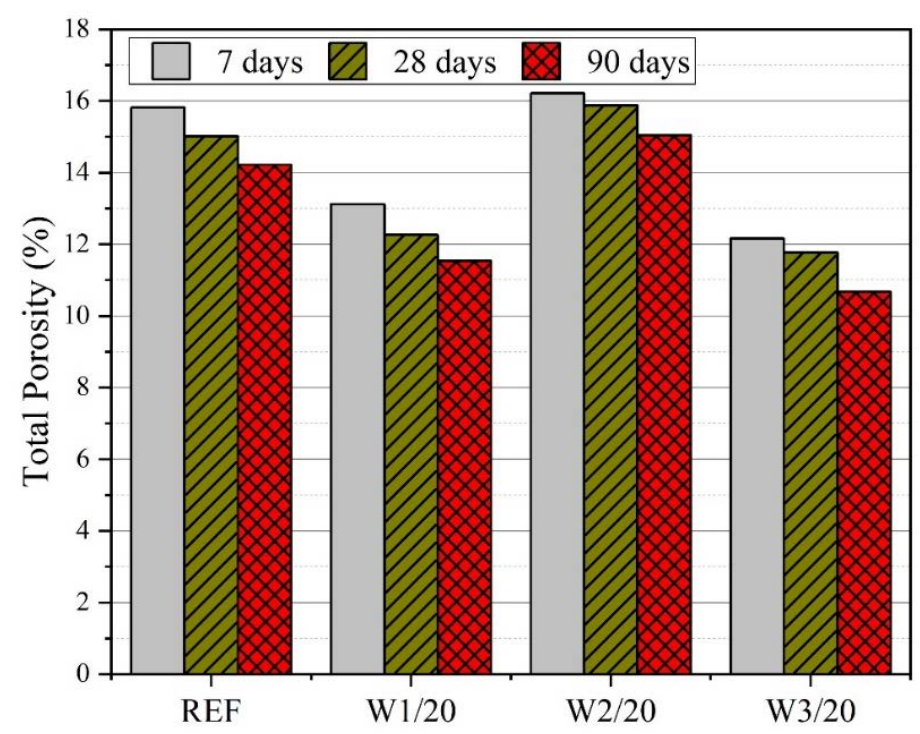

Figure 7. Total porosity of mortar specimens.

\subsection{Ultrasonic Pulse Velocity}

UPV test was carried out on the mortars at 7, 28, and 90 days of hydration. Figure 8 depicts the results of UPV test. UPV values augmented with growing curing age. For instance, the control (REF) specimens demonstrated a UPV value of 3650,3986 , and $4078 \mathrm{~m} / \mathrm{s}$ at 7, 28, and 90 days of curing. It is due to the formation of hydration products with curing age causing a densified microstructure. On the contrary, the inclusion of fine-sized WSA particles caused an enhanced UPV value. This enhancement was much higher for finer ash particles. For example, a UPV value of $3768 \mathrm{~m} / \mathrm{s}, 4101 \mathrm{~m} / \mathrm{s}$, and $4200 \mathrm{~m} / \mathrm{s}$ was measured for W1/20 mortar specimens at 7, 28, and 90 days of curing.

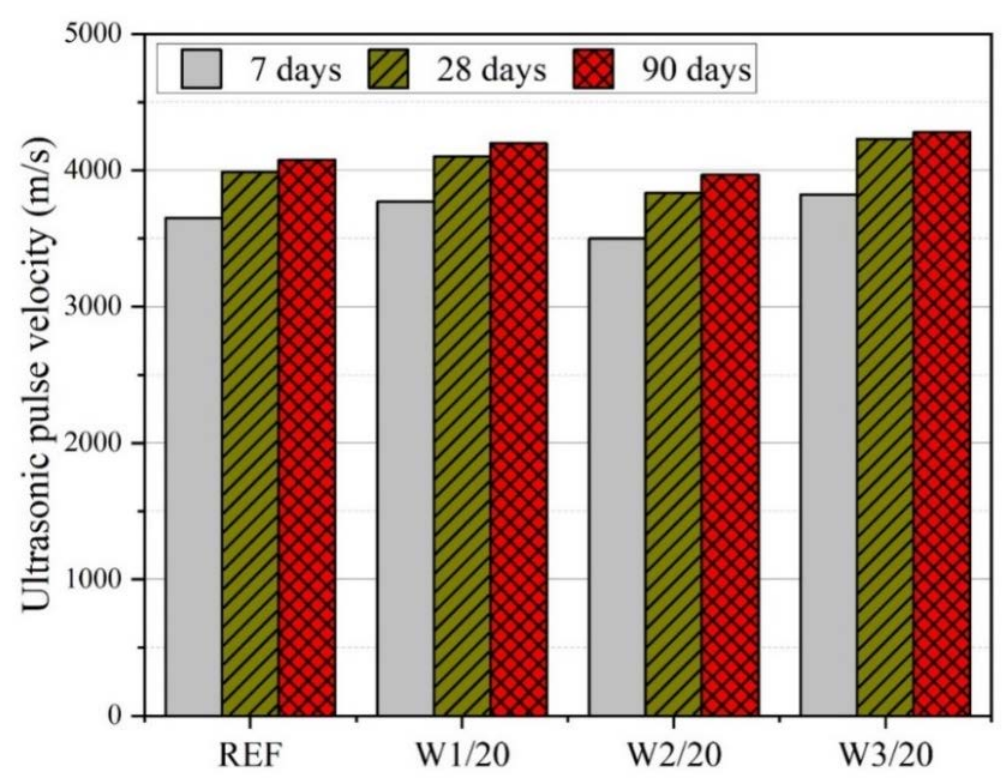

Figure 8. UPV test results for mortar specimens. 
W2/20 and W3/20 mortar specimens demonstrated UPV value of 3500 and $3822 \mathrm{~m} / \mathrm{s}$ at 7 days; 3834 and $4231 \mathrm{~m} / \mathrm{s}$ at 28 days; 3966 and $4282 \mathrm{~m} / \mathrm{s}$ at 90 days, respectively. It is evident from the UPV results that the addition of W2 type ash particles (Sp. Surface area: $7251 \mathrm{~cm}^{2} / \mathrm{g}$ ) caused a reduction in the pulse velocity. A reduction of $4.1 \%, 3.8 \%$, and $2.7 \%$ in the UPV values was witnessed for W2/20 mortar specimens compared to control mortars. It indicates that the incorporation of finer ash particles refined pore structure of the mortars and led to increased UPV values. This refinement was caused by the pozzolanic as well filler effect of WSA. Comparable findings were reported in the previous research studies. Goyal et al. has reported that increase in the UPV values was due to the filling effect of fine particles of SCBA [40]. Similarly, in another study, it has been concluded that pozzolanic and micro-filling effect of RHA particles caused a densification in the microstructure which resulted in an enhanced UPV values [41].

\subsection{Scanning Electron Microscopy}

Microstructure of the mortar specimen cured for 28 days were analyzed via scanning electron microscopy. Figure 9 displays the SEM images of the control specimen and the specimens containing various types of ashes. Figure 9a depicts the SEM image of REF mortar specimen. Mortars without WSA presented a porous microstructure with an increased amount of plate-like portlandite $(\mathrm{CH})$. Contrary to this, the inclusion of WSA densified the microstructure of the mortars. This improvement was caused due to the pozzolanic and filler effects of WSA particles. In particular, the inclusion of fine-sized ash particles demonstrated enhanced densification as compared to the coarse-sized ash particles. For instance, from the SEM images (Figure $9 b, d$ ), the prevalence of dense structured C-S-H gel is visible. Accordingly, these specimens displayed a refined and dense microstructure due to pozzolanic and filler effect of finer ash particles. On the other hand, the microstructure of the mortar specimens made with W2 type ash (Figure 9c) depicted more porosity and reduced amount of C-S-H gel in comparison with specimens made with $\mathrm{W} 1$ and W2 type ashes. These results confirm that the inclusion of finer WSA particles improved the microstructure of the mortars. It is because of this reason, compressive and flexure strength increased and pore structure of the mortar specimens improved which resulted in higher UPV values and reduced total porosity. In summary, pozzolanic and filler effects and heterogeneous nucleation were responsible for the improved performance of various ash particles $[24,37,42]$.
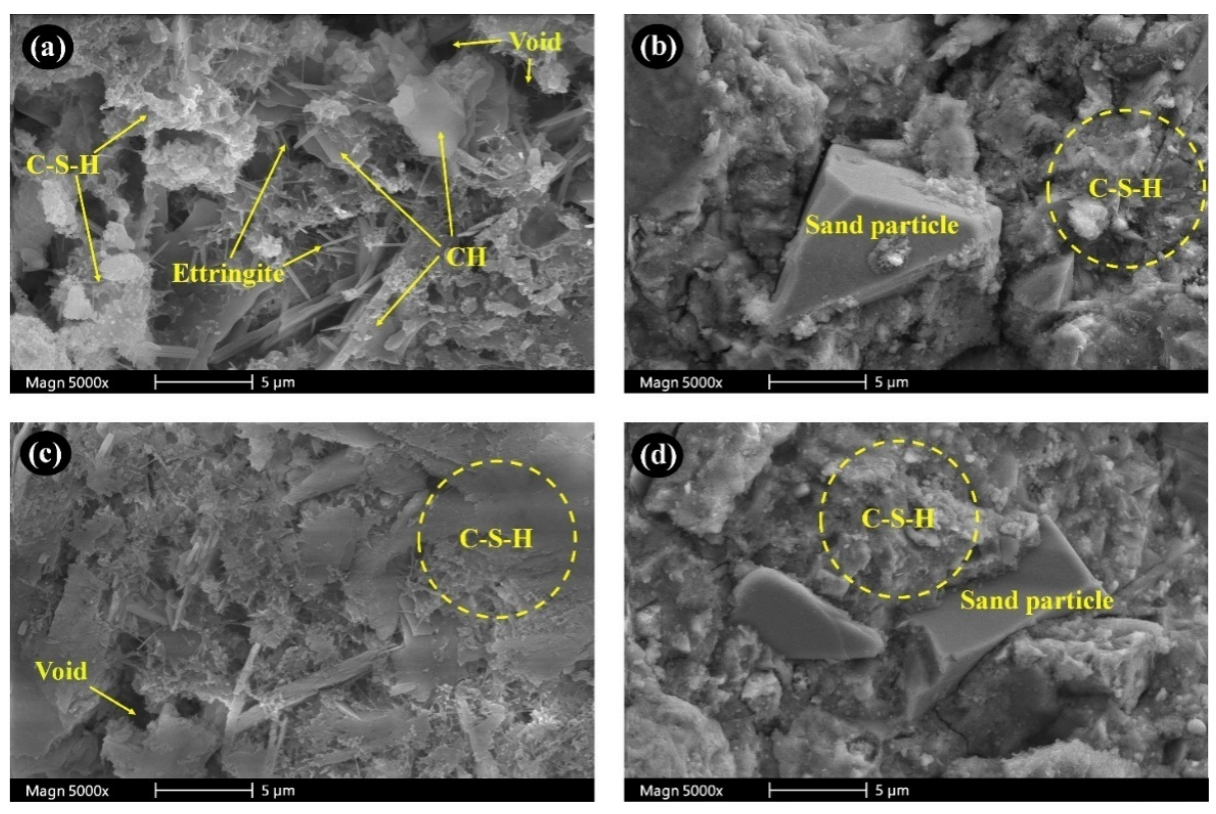

Figure 9. SEM images of (a) control, (b) W1/20, (c) W2/20, and (d) W3/20 mortar specimens at 28 days. 


\section{Conclusions}

In this study, the influence of milling techniques on the pozzolanic activity of wheat straw ash (WSA) was investigated. Two types of WSA were created by milling ash in ball mill and disintegrator mill separately, and a third type of ash was created by milling ash first in ball mill and then in disintegrator mill. The grinding of ash particles redefined the particle size distribution by reducing size and enhancing specific surface area. The crystallinity of silica present in the ashes reduced due to the grinding effect. Finest ash particles were obtained by use of both grinding techniques: disintegrator milling and ball milling. Paste specimens with finer ash particles showed an amplified hydration reaction at the early ages, an enhanced compressive and flexure strength. Similarly the incorporation of finer ash particles expressively reduced the $\mathrm{CH}$ content in the paste specimens cured for 28 days. Finer ash particles refined the pore structure of the mortar specimens resulting in an improved microstructure, reduced total porosity and enhanced ultrasonic pulse velocity values. Based on the results of this study, it can be concluded that WSA with an enhanced performance can be obtained by applying a combination of disintegrator and ball milling techniques.

Author Contributions: Conceptualization, A.Q. and A.u.R.; methodology, A.Q.; validation, A.Q. and H.G.K.; formal analysis, A.Q.; investigation, A.Q; data curation, A.Q., A.u.R. and I.K.J.; writing—original draft preparation, A.Q.; writing - review and editing, A.Q. and E.K.; visualization, A.Q.; supervision, H.G.K.; funding acquisition, H.G.K. All authors have read and agreed to the published version of the manuscript.

Funding: This research was funded by Ministry of Education through National Research Foundation of Korea (NRF-2019R1I1A1A01061805) under Basic Science Research Program.

Conflicts of Interest: The authors declare no conflict of interest.

\section{References}

1. Ludwig, H.-M.; Zhang, W. Research review of cement clinker chemistry. Cement Concr. Res. 2015, 78, 24-37. [CrossRef]

2. Kajaste, R.; Hurme, M. Cement industry greenhouse gas emissions-management options and abatement cost. J. Clean. Prod. 2016, 112, 4041-4052. [CrossRef]

3. Huang, L.; Krigsvoll, G.; Johansen, F.; Liu, Y.; Zhang, X. Carbon emission of global construction sector. Renew. Sustain. Energy Rev. 2018, 81, 1906-1916. [CrossRef]

4. Torres-Carrasco, M.; Puertas, F. Alkaline activation of different aluminosilicates as an alternative to Portland cement: Alkali activated cements or geopolymers. Rev. Ing. Const. 2017, 32, 05-12. [CrossRef]

5. Ke, J.; McNeil, M.; Price, L.; Khanna, N.Z.; Zhou, N. Estimation of CO2 emissions from China's cement production: Methodologies and uncertainties. Energy Policy 2013, 57, 172-181. [CrossRef]

6. Monteiro, P. Concrete: Microstructure, Properties, and Materials; McGraw-Hill Publishing: New York, NY, USA, 2006.

7. Qudoos, A.; Jeon, I.K.; Kim, S.S.; Lee, J.B.; Kim, H.G. Utilization of Waste Polysilicon Sludge in Concrete. Materials 2020, 13, 251. [CrossRef] [PubMed]

8. Mehta, P.K. Mineral admixtures for concrete-an overview of recent developments. In Proceedings of the Advances in Cement and Concrete, Durham, NC, USA, 24-29 July 1994; pp. 243-256.

9. Nair, D.G.; Fraaij, A.; Klaassen, A.A.; Kentgens, A.P. A structural investigation relating to the pozzolanic activity of rice husk ashes. Cement Concr. Res. 2008, 38, 861-869. [CrossRef]

10. Xu, W.; Lo, T.Y.; Memon, S.A. Microstructure and reactivity of rich husk ash. Constr. Build. Mater. 2012, 29, 541-547. [CrossRef]

11. Yu, Q.; Sawayama, K.; Sugita, S.; Shoya, M.; Isojima, Y. The reaction between rice husk ash and Ca (OH) 2 solution and the nature of its product. Cement Concr. Res. 1999, 29, 37-43. [CrossRef]

12. Munshi, S.; Sharma, R.P. Experimental Investigation on Strength and Water Permeability of Mortar Incorporate with Rice Straw Ash. Adv. Mater. Sci. Eng. 2016, 2016, 9696505. [CrossRef]

13. Amin, N.-U. Use of bagasse ash in concrete and its impact on the strength and chloride resistivity. J. Mater. Civ. Eng. 2010, 23, 717-720. [CrossRef]

14. Jaturapitakkul, C.; Kiattikomol, K.; Tangchirapat, W.; Saeting, T. Evaluation of the sulfate resistance of concrete containing palm oil fuel ash. Constr. Build. Mater. 2007, 21, 1399-1405. [CrossRef] 
15. Adesanya, D.; Raheem, A. A study of the workability and compressive strength characteristics of corn cob ash blended cement concrete. Constr. Build. Mater. 2009, 23, 311-317. [CrossRef]

16. Top Wheat Producing Countries 2017/2018. Available online: https://www.statista.com/statistics/237908/ global-top-wheat-producing-countries/ (accessed on 9 June 2018).

17. Pan, X.; Sano, Y. Fractionation of wheat straw by atmospheric acetic acid process. Bioresour. Technol. 2005, 96, 1256-1263. [CrossRef] [PubMed]

18. Biricik, H.; Aköz, F.; lhan Berktay, I.; Tulgar, A.N. Study of pozzolanic properties of wheat straw ash. Cement Concr. Res. 1999, 29, 637-643. [CrossRef]

19. Al-Akhras, N.M.; Abu-Alfoul, B.A. Effect of wheat straw ash on mechanical properties of autoclaved mortar. Cement Concr. Res. 2002, 32, 859-863. [CrossRef]

20. Goyal, A.; Kunio, H.; Ogata, H.; Garg, M.; Anwar, A.; Ashraf, M. Synergic effect of wheat straw ash and rice-husk ash on strength properties of mortar. J. Appl. Sci. 2007, 7, 3256-3261.

21. Khushnood, R.A.; Rizwan, S.A.; Memon, S.A.; Tulliani, J.-M.; Ferro, G.A. Experimental investigation on use of wheat straw ash and bentonite in self-compacting cementitious system. Adv. Mater. Sci. Eng. 2014, 2014, 832508. [CrossRef]

22. Binici, H.; Yucegok, F.; Aksogan, O.; Kaplan, H. Effect of corncob, wheat straw, and plane leaf ashes as mineral admixtures on concrete durability. J. Mater. Civ. Eng. 2008, 20, 478-483. [CrossRef]

23. Al-Akhras, N.M. Durability of wheat straw ash concrete exposed to freeze-thaw damage. Proc. Inst. Civ. Eng.-Constr. Mater. 2011, 164, 79-86. [CrossRef]

24. Cordeiro, G.C.; Kurtis, K.E. Effect of mechanical processing on sugar cane bagasse ash pozzolanicity. Cement Concr. Res. 2017, 97, 41-49. [CrossRef]

25. ASTM. ASTM C150: Standard Specification for Portland Cement; ASTM Standards: West Conshohocken, PA, USA, 2007.

26. Biricik, H.; Aköz, F.; Türker, F.; Berktay, I. Resistance to magnesium sulfate and sodium sulfate attack of mortars containing wheat straw ash. Cement Concr. Res. 2000, 30, 1189-1197. [CrossRef]

27. ASTM. Standard Test Method for Compressive Strength of Hydraulic Cement Mortars (Using 2-in. or [50-mm] Cube Specimens); ASTM Standards: West Conshohocken, PA, USA, 2007.

28. ASTM. Standard Test Method for Flexural Strength of Hydraulic-Cement Mortars; ASTM Standards: West Conshohocken, PA, USA, 2002.

29. Walker, H.N.; Lane, D.S.; Stutzman, P.E. Petrographic Methods of Examining Hardened Concrete: A Petrographic Manual. Revised 2004; The National Academies of Sciences, Engineering, and Medicine: Washington, DC, USA, 2006.

30. ASTM. Standard Test Method for Pulse Velocity through Concrete; ASTM Standards: West Conshohocken, PA, USA, 2009.

31. ASTM. Standard Specification for Coal Fly Ash and Raw or Calcined Natural Pozzolan for Use in Concrete; ASTM Standards: West Conshohocken, PA, USA, 2003.

32. Jamil, M.; Khan, M.; Karim, M.; Kaish, A.; Zain, M. Physical and chemical contributions of Rice Husk Ash on the properties of mortar. Constr. Build. Mater. 2016, 128, 185-198. [CrossRef]

33. Cordeiro, G.C.; Toledo Filho, R.D.; Fairbairn, E.d.M.R. Use of ultra-fine sugar cane bagasse ash as mineral admixture for concrete. ACI Mater. J. 2008, 105, 487-493.

34. Ganesan, K.; Rajagopal, K.; Thangavel, K. Evaluation of bagasse ash as supplementary cementitious material. Cem. Concr. Compos. 2007, 29, 515-524. [CrossRef]

35. Xu, W.; Lo, Y.T.; Ouyang, D.; Memon, S.A.; Xing, F.; Wang, W.; Yuan, X. Effect of rice husk ash fineness on porosity and hydration reaction of blended cement paste. Constr. Build. Mater. 2015, 89, 90-101. [CrossRef]

36. ASTM. Standard Practice for Measuring Hydration Kinetics of Hydraulic Cementitious Mixtures Using Isothermal Calorimetry; ASTM Standards: West Conshohocken, PA, USA, 2009; Volume 4.

37. Lawrence, P.; Cyr, M.; Ringot, E. Mineral admixtures in mortars: Effect of inert materials on short-term hydration. Cement Concr. Res. 2003, 33, 1939-1947. [CrossRef]

38. Shaikh, F.U.; Supit, S.W. Compressive strength and durability properties of high volume fly ash (HVFA) concretes containing ultrafine fly ash (UFFA). Constr. Build. Mater. 2015, 82, 192-205. [CrossRef]

39. Shatat, M. Hydration behavior and mechanical properties of blended cement containing various amounts of rice husk ash in presence of metakaolin. Arab. J. Chem. 2016, 9, S1869-S1874. [CrossRef] 
40. Ajay, G.; Hattori, K.; Ogata, H.; Ashraf, M. Processing of sugarcane bagasse ash and reactivity of ash-blended cement mortar. Trans. Jpn. Soc. Irrig. Drain. Rural Eng. 2009, 77, 243-251.

41. Safiuddin, M.; West, J.; Soudki, K. Hardened properties of self-consolidating high performance concrete including rice husk ash. Cement Concr. Compos. 2010, 32, 708-717. [CrossRef]

42. Cordeiro, G.; Toledo Filho, R.; Tavares, L.; Fairbairn, E. Pozzolanic activity and filler effect of sugar cane bagasse ash in Portland cement and lime mortars. Cement Concr. Compos. 2008, 30, 410-418. [CrossRef]

(C) 2020 by the authors. Licensee MDPI, Basel, Switzerland. This article is an open access article distributed under the terms and conditions of the Creative Commons Attribution (CC BY) license (http://creativecommons.org/licenses/by/4.0/). 